\title{
Prejudice and the learning of biracial influence structures
}

DAVID W. LEWIT and PAUL J. SHANLEY, University of Hawaii, Honolulu, Hawaï 96822

Sixty-four white undergraduates were instructed to learn who influences whom in eight hypothetical factory work groups, varying in racial distribution and transitivity. Transitive structures were learned more easily than nontransitive. Contrary to prediction, pro-Negro Ss were poor at learning Negro-dominated structures, especially when the structure was not transitive, and leamed white-dominated structures very well when they were transitive. Pro-white Ss generally learned better than pro-Negro Ss. Pro-Negro Ss may be more anxious than pro-white, which may interfere with learning complex nontransitive structures.

Structural balance is a principle of cognitive organization applied to groups which leads an $\mathrm{O}$ to expect that persons who like each other have positively correlated likes and dislikes, whereas those who dislike each other have negatively correlated likes and dislikes. The principle has been shown to apply both to prediction and to learning. DeSoto \& Kuethe (1959) and many others (see Zajonc, 1968) have shown that if $A$ likes $B$, and $B$ likes $X$, then the $O$ tends to predict that $\mathbf{A}$ also likes $\mathrm{X}$, or that if $\mathbf{B}$ dislikes $\mathrm{X}$, that $A$ is predicted also to dislike $X$.

The application of the balance principle to learning (DeSoto, 1960) refers to generalization or to extinction and reversal learning. That is, if a balanced set of relationships is to be learned, the balance principle will be generalized as in overlearning, so that the correct responses are made and performance on a le arning trial is facilitated. However, if an imbalanced set is to be learned, the balance principle will be generalized so that some incorrect responses are made. Performance on such a learning trial will be incorrect as in early extinction trials, where what has been learned is no longer confirmed, and learning of correct associations is delayed.

The difference between ordinary learning and leaming of a particular social structure is that in the former what is learned in early trials is generalized to later trials, whereas in the latter what is presumed is generalized to early trials. The presumption may be the result of learning of various sets of likes and dislikes by repeated observation during socialization, which are likely to be balanced (Kogan \& Tagiuri, 1958), or of internalizing norms or prejudices by any means.

Balance is one of a number of principles which tend to determine relational predictions or to bias relational learning. The cognition of attitudinal relations also involves presumptions of dyadic symmetry (if A likes B, B likes A) and positivity (A likes rather than dislikes B) (Zajonc \& Burnstein, 1965). Influence relations, on the other hand, tend to be cognized with asymmetric dyads (if $A$ influences B, B does not influence $A)$, differentiated in rank $(A$, $B, C$, etc., differ in degree of influence), authority-rank correlation (if $A$ has most authority, $A$ has most influence), and transitivity (if $A$ influences $B$, and $B$ influences $C$, then $A$ influences $C$ ) (DeSoto, 1960; Lewit, 1963; van Kreveld \& Zajonc, 1966). Lewit (1963) also showed that the presumption of authority-rank correlation operates among high but not low authoritarians.

The present study deals with the learning of influence relations, with particular concern for the biasing presumptions of racially prejudiced Ss. The social structures to be learned include influence relations among whites and Negroes, who may be presumed by prejudiced Ss to differ in disposition to influence one another, much as would persons with differing rank or authority. Specifically, the hypotheses are (a) that all Ss, regardless of prejudice, will learn transitive structures more easily than intransitive ones, and (b) that pro-Negro $S$ s will learn more easily than pro-white Ss those sets of relationships in which Negroes influence whites. In the second hypothesis, it is assumed that pro-white Ss more consistently expect whites to influence Negroes and not vice versa.

\section{METHOD}

The attitudes of 240 white undergraduates at the University of Massachusetts toward Negroes and whites were measured. The test (Rokeach, 1960) required each $S$ to say how friendly he could be with "a white person who is for socialized medicine," "a Negro who is for socialized medicine," and 15 other pairs of items dealing with a variety of social beliefs, presented in a random order. The mean net score for all Ss was 5.5 in the pro-white direction, with a standard deviation of 10.7. For the same test, Rokeach found split-half reliabilities of .81 to .83 . Scores correlated .42 with the Negro Stereotypes scale of Katz, Samoff, \& McClintock (1956), whose reliability has not been reported but whose construct validity has been established. In the same sample of 61 students, the Rokeach test correlated .42 with the California F scale.

Sixty-four students were chosen from the extremes of the distribution as experimental Ss. These were 16 males and 16 females scoring 11-39 in the pro-white direction, and 16 of each scoring $1-13$ points in the pro-Negro direction. Each $S$ learned who influenced whom in one of eight four-man groups, by the method of paired associates. Ss were instructed: "This is a study in social interaction. Four men work in a factory. All four men are between the ages of 21 and 25 and are not married." Then 16 Ss were told that "all four men are white." Sixteen others were told "all four men are Negro." The rest were told "two of these men are white and two are Negro." All Ss were then told, "Some of these four men are more influential than the others. To 'influence' someone means to have some degree of control over his actions. Your task will be to learn who influences whom, and who does not influence whom among the four men." Further instructions were given to indicate that a pair of schematic faces with associated names would be projected for $5 \mathrm{sec}$ on the screen before the $\mathrm{Ss}$, and that each was to guess within $8 \mathrm{sec}$ whether the man on the left "influences" or "does not influence" the man on the right. Negro faces were drawn with shading and with wider noses than white faces.

Seated in partitioned tablet armchairs, Ss responded by moving a three-position toggle switch. Within $10 \mathrm{sec}$ of stimulus onset, the E projected the correct answer word(s) between the two faces on the ecreen, and required the $S s$ to correct their switch movement if it was wrong. The 12 influence relations were shown in a random order at $20-\sec$ intervals. Eight such trials were presented with a 50 -sec interval between trials.

The eight structures are shown in Fig. 1. Half are transitive and half are nontransitive (two of four triples are intransitive). One of each transitivity type was all-white and one all-Negro. One of each type was biracial with two whites more influential than the two Negroes, and the remaining one of each type was biracial with two Negroes more influential than the two whites. Eight $\mathrm{Ss}_{3}$ were assigned to each structure, two from each sex-attitude cross classification.

\section{RESULTS}

For each $S$, the number of correct responses was calculated, the maximum possible being 96 over the eight trials of 12 relations each. Means are shown in Fig. 2. A four-way analysis of variance was done, with transitivity, racial distribution, S's attitude, and $S$ 's sex as sources.

Hypothesis (a) was confirmed with a significant main effect for transitivity 


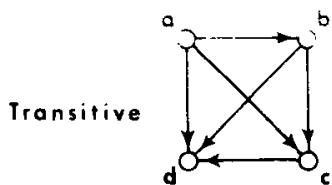

1

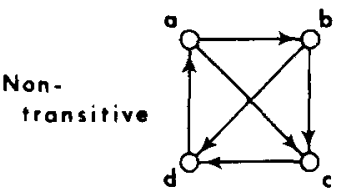

2

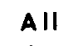

White

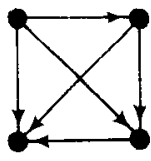

3

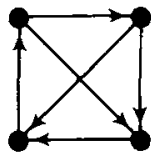

4

All

Negro

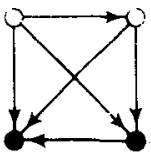

5

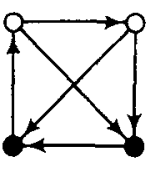

6

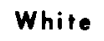

Dominant

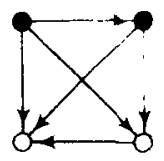

7

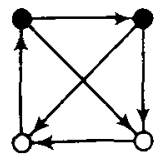

8

Negro

Dominant $(\mathrm{p}<.01)$. Hypothesis (b) was not confirmed in a simple Racial Distribution by Attitude interaction, but there was a triple interaction involving these factors and transitivity $(\mathrm{p}<.05)$. At the level of nontransitive structures, pro-Negro $S$ s did poorly as expected on white-dominant structures, differing significantly from pro-whites $(p<.01$, using Winer's method of individual comparisons), but were not superior to pro-white Ss on Negro-dominant structures. At the level of transitive structures, pro-Negro Ss did poorly on all-white structures relative to pro-whites $(p<.01)$, but on biracial structures showed the reverse of predictions: they did better on white-dominated than on Negro-dominated structures $(p<.05)$, and tended (n.s.) to do better on the former than pro-white $S$ s.

Another unexpected finding is the overall superiority of the pro-white Ss in learning all types of structures $(p<.05)$. Contributing

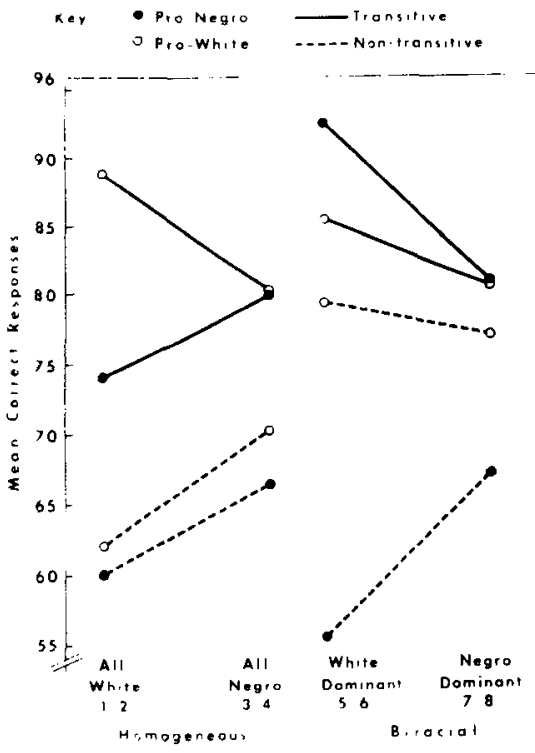

Fig. 2. Learning performances of pro-white and pro-Negro Ss. to this is their relatively high performance in dealing with nontransitive structures when composition was biracial $(p<.05)$.

\section{DISCUSSION}

The effect of transitivity proved to be powerful in this study as it has been in studies not involving race. What remains to be explained is the poor performance of pro-Negro Ss dealing with influence relations in biracial groups where Negroes are relatively influential, and the generally superior performance of pro-white Ss. Focusing on the latter, it is conceivable that pro-whites may have depersonalized the elements to be associated under certain conditions, and treated the relations as mechanical. This is reasonable especially in the biracial groups, which might pose a greater threat to Ss who would prefer not to associate with Negroes than to those who have a racial preference of lesser magnitude. This supposition proved insubstantial when postexperimental questionnaires were examined. Ss were asked to characterize the groups to which they had just been exposed, and to describe their method of learning. Many failed to assimilate stimulus faces and structures to known persons or groups, and some used mnemonic devices, but these depersonalizing approaches were as common among pro-whites who learned poorly in the biracial conditions as among those who learned well.

A more satisfactory explanation for all of the effects emphasizes the role of anxiety among pro-Negro $\mathrm{Ss}$ in learning complex sets of relations. Suppose for the moment that pro-Negro Ss were more anxious than their moderately prejudiced counterparts whose pro-white attitude more nearly reflects the modal tendency of their society. Spence (1958) and Sarason \& Palola (1960) have shown that persons with an enduring disposition toward anxiety perform better than nonanxious persons on various simple learning lasks. but are poorer at learning complex lasks. This line of reasoning lits
Fig. 1. Structures presented for learning. White circles indicate white members, and black circles indicate Negro members. Arrows indicate direction of influence. Where no arrow is shown, Ss were required to learn "does not influence." Members were named Bill, Jim, Ray, and Stan (DeSoto, 1960).

very well with the results we have obtained. That is, our presumably highly anxious pro-Negro Ss learned very well the simple transitive whites-dominate-Negroes structure better than any other group, but they performed more poorly than any other group on the more complex nontransitive structures of mixed racial composition. This explanation assumes that pro-Negro Ss had high drive resulting from a combination of personal anxiety, a biracial situation, and the disequilibrium (or frustration) arising from intransitives. Pro-white Ss, lacking personal anxiety, may have had a more nearly optimal drive level for dealing with complex (nontransitive) biracial groups.

To test this attitude-anxiety assumption, 98 Ss from the same population were given the same attitude test and the Sarason Test Anxiety Questionnaire (Sarason \& Palola, 1960). A correlation of $.26, p<.02$, was obtained. Though probably attenuated by the low reliability of the attitude test, the relationship was in the direction of greater anxiety for pro-Negro Ss.

The effects of prejudice and other personality characteristics in the learning of interpersonal relations are important in their own right, e.g., with respect to newcomers entering structured groups. To test Hypothesis (b) without the complexities of learning, future studies might use the prediction technique with pro-white and pro-Negro Ss.

\section{REFERENCES}

DeSOTO, C. B. Learning a social structure. Journal of Abnormal \& Social Psychology, 1960,60, 417-421.

DeSOTO, C. B., \& KUETHE, J. L. Subjective probabilities of interpersonal relationships. Journal of Abnormal \& Social Psychology, 1959, 59, 290-294.

KATZ, D., SARNOFF, I., \& MCCLINTOCK, C. Ego-defense and attitude change. Human Relations, 1956, 9, 27.45.

KOGAN, N., \& TAGIURI, R. Interpersonal preference and cognitive organization. Journal of Abnormal \& Social Psychology, 1958, 56, 113-116.

LEWIT, D. W. The learning of mixed power/liking relationships in small social structures. Paper read at the meeting of the Lastern Psychological Association, New York, A pril 1963

ROKEACH, M. The open and closed mind. New York: Basic Books, 1960.

SARASON, I. G.. \& PAI.OLA, 1: G. The rclationship of ters and general anxiety. difficulty of task. and experimental instructions to performanee. Journal of lexperimental Paychology, 1960.59, 185-191. 
SPLANCL, K. W. A theory of emotionatly based drive (D) and its relation to performance in simple learning situations. American Psychologist, 1958, 13, 131-141.

van KREVLLD, D., \& ZAJONC, R. B. The learning of influence structures. Journal of Personality, 1966, 34, 205-223

ZAJONC, R. B. Cognitive theories in social psychology. In G. Lindzey and E. Aronson (Eds.), Handbook of social psychology. (2nd ed.) Vol. 1. Reading. Mass: Addison-Wesley, 1968.

ZAJONC, R. B., \& BLRNSTEIN, E. Structural balance, reciprocity, and positivity as sources of cognitive bias. Journal of Personality, 1965, 33. $570-583$

NOTE

1. This rescarch was supported by Grant M4 164 from the National Institute of Mental Health.

\section{Interpersonal attraction as a function of the accuracy of personal evaluations'}

\section{JAY HEWITT, University of Victoria, Victoria, B.C., Canada}

Each $S$ was evaluated by four confederates. One evaluation was favorable and accurate, one was favorable and inaccurate, one was unfavorable and accurate, and one was unfavorable and inaccurate. After receiving these evaluations, the $S$ rated his attraction to each of the confederates. Attraction was greater when the evaluation was favorable than when it was unfavorable and attraction was greater when the evaluation was accurate than when it was inaccurate.

According to the cognitive consistency theory of interpersonal attraction, the attraction of one person (P) to another person $(\mathrm{O})$ is a function of the similarity between $O$ 's perception of $P$ and of P's perception of himself (Deutsch \& Solomon, 1959). Two major experimental designs can be employed to test this theory. In the first design, consistency is varied by manipulating the S's opinion of himself. Two groups of Ss are employed, one with a favorable opinion of themselves and one with an unfavorable opinion. Each $S$ is evaluated favorably or unfavorably by someone else. It is assumed that a favorable evaluation will be more consistent with the self-perception of someone with a high opinion of himself than with the self-perception of someone with a low opinion of himself. If this assumption is correct, people who receive a favorable evaluation should be more attracted to their evaluator if they have a high opinion of themselves than if they have a low opinion of themselves. It is also assumed that an unfavorable evaluation will be more consistent with the self-perception of someone with a low opinion of himself than with the self-perception of someone with a high opinion of himself. If this assumption is correct, people who receive an unfavorable evaluation should be more attracted to their evaluator if they have a low opinion of themselves than if they have a high opinion of themselves.

Support for the above predictions has been obtained when the evaluations concern the S's ability to succeed on a particular task (Deutsch \& Solomon, 1959). Consistency theory has not been supported when the evaluations concern the more enduring characteristics of the S's personality. Under these conditions, Ss with low self-esteem are more attracted to people who evaluate them favorably (Walster, 1965) and are more hostile to people who evaluate them unfavorably (Dittes, 1959) than are people with high self-esteem.

One problem with the first experimental design is that consistency is confounded with self-esteem. An evaluation that is consistent with the self-perception of someone with high self-esteem is inconsistent for someone with low self-esteem and vice versa. The failure of studies employing this design to support consistency theory may reflect not so much the inadequacy of consistency theory as the more powerful effects of self-esteem.

The purpose of the present study was to demonstrate that consistency theory does hold when the evaluations concern the more enduring characteristics of the S's personality. To avoid the problems of confounding consistency with self-esteem, an alternative experimental design was employed. In this design, consistency was manipulated by varying the content of the evaluations. The evaluation was either based on what the $S$ had previously said about himself (accurate evaluation) or was not based on this information (inaccurate evaluation). Regardless of whether the evaluation was favorable or unfavorable, it was predicted that the $S$ would be more attracted to his evaluator when the evaluation was accurate than when it was inaccurate.

\section{METHOD}

The Ss consisted of 12 male undergraduates recruited from an introductory psychology class. At each experimental session, two Ss were run simultaneously (although neither was aware of the other's presence).

Upon arriving for the experiment, the $S$ was seated in a small, soundproof cubicle and handed two lists of adjectives, one marked "desirable characteristics" and one marked "undesirable characteristics." On the first list, the $S$ was asked to put a checkmark beside the five words that best described his desirable characteristics and, on the second list, the five words that best described his undesirable characteristics. Each list contained 40 personality-trait adjectives (cf. Anderson, 1968), half of which were high in "desirability" (e.g., sincere, good-humored, intelligent) and half of which were low in "desirability" (e.g., antisocial, immature, self-centered).

After the $\mathrm{S}$ had described his desirable and undesirable characteristics, he was (erroneously) informed that there were four other people participating in the experiment, Ss A, B, C, and D. (In reality, A, $B, C$, and $D$ were confederates.) The $S$ was then handed a sheet which summarized the procedure. The sheet contained the following information. In the first phase of the experiment, the other participants (A, B, $C$, and D) would listen while E (the S) described himself. A, B, C, and D would then be asked to give their impression of $E$. Since all the rooms were equipped with intercoms, A, B, C, and D-would be able to hear E's self-description and $E$ would be able to listen while $A, B, C$, and $D$ gave their impression of him. (However, A, B, C, and D would not be able to hear one another's evaluation of $E$.) After the procedure had been explained, the $S$ was handed four identical lists of adjectives, informed that each evaluation would consist of three adjectives, and requested to put a checkmark beside the adjectives comprising each evaluation (the first list being used to record A's impression, the second list being used to record B's impression, etc.).

After the first $S$ had received the preliminary instructions, the procedure was repeated with the second $S$ (who was in a different room). The experimenter then retired to an adjoining room, taking with him the sheets on which the Ss had indicated their desirable and undesirable 